\title{
The ascent of POEM: Double-tunnel per oral endoscopic re-myotomy
}

\author{
Bryan M. Burt, MD
}

\author{
From the Division of Thoracic Surgery, Baylor College of Medicine, Houston, Tex. \\ Disclosures: Author has nothing to disclose with regard to commercial support. \\ Received for publication Feb 4, 2016; accepted for publication Feb 5, 2016; available ahead of print March 11, \\ 2016. \\ Address for reprints: Bryan M. Burt, MD, Division of Thoracic Surgery, Baylor College of Medicine, Houston, \\ TX 77030 (E-mail: bryan.burt@bcm.edu). \\ J Thorac Cardiovasc Surg 2016;151:e103-4 \\ $0022-5223 / \$ 36.00$ \\ Copyright $(2016$ by The American Association for Thoracic Surgery \\ http://dx.doi.org/10.1016/j.jtcvs.2016.02.010
}

Per oral endoscopic myotomy (POEM) is an advanced endoscopic procedure for classic (type II) achalasia that is rapidly evolving and is well on its way to becoming a standard-of-care treatment for this disease. Since the first published report in 2008 on the use of POEM in humans, a proliferation of published series have established POEM as a safe, feasible, and definitive treatment for achalasia, demonstrating comparable results to the time-honored Heller myotomy. .,2 $^{1,2}$

As collective experience with a promising new technology matures, the indications for the technology expand. POEM operators are taking on more anatomically challenging cases, and POEM is now being applied in a variety of esophageal motility disorders. Successful application of POEM has been reported in small numbers of patients with diffuse esophageal spasm, hypertensive lower esophageal sphincter, type III spastic achalasia, nutcracker esophagus, and jackhammer esophagus. ${ }^{3}$ It is predicted that POEM may prove superior to laparoscopic Heller myotomy for patients with spastic esophageal motility disorders such as type III achalasia and diffuse esophageal spasm, because the myotomy created by POEM can be extended more proximally onto the body of the esophagus.

The role of POEM for recurrence following myotomy (surgical and endoscopic) is evolving. The rate of failure of Heller myotomy for achalasia has been reported to range from $3.5 \%$ to $15.0 \%$. ${ }^{4}$ These failures can be due to disease factors, such as persistent or recurrent achalasia, and to surgical factors, including inadequate myotomy or scarring and fibrosis. Treatment of patients with persistent or recurrent symptoms following myotomy includes temporizing measures, such as endoscopic dilation or injection of botulism toxin, and definitive measures, such as redo myotomy and esophagectomy (in some cases). Redo Heller myotomy results in relatively good functional outcomes; however, it generally has a lower success rate and a higher rate of morbidity when compared with initial myotomy. From a technical perspective, reoperative surgical myotomy is more difficult than initial myotomy owing to postsurgical surgical adhesions and fibrosis at the previous myotomy site, the latter of which can result in higher rates of mucosal

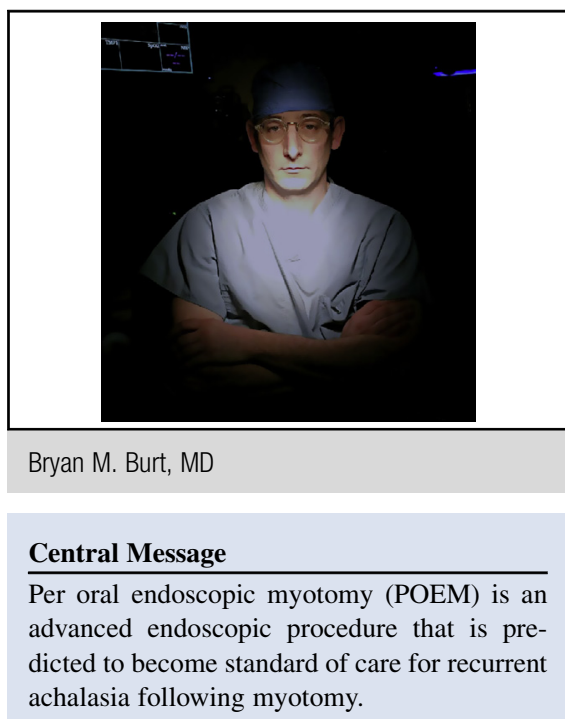

See Article page e101.

perforation. Per oral endoscopic re-myotomy (POEreM) is an attractive alterative to redo surgical myotomy, and has several potential advantages. First, POEM is an entirely endoscopic approach, which obviates many of the challenges associated with reoperative surgery. Second is the flexibility in choosing the axis of the myotomy, which when performed endoscopically can more easily avoid the area in which the first myotomy was performed. Another advantage is direct visualization of the submucosal layer during myotomy, which may mitigate the risk of fullthickness perforation.

As operators become more comfortable with submucosal endoscopy, POEM will become routine in patients with failed prior treatments. In a recent international survey of 841 POEM cases collected from high-volume centers around the world (with high volume defined as $>30$ cases per center), $43 \%$ of POEM procedures were performed in patients with failed prior treatment. Previous treatments included botulism toxin injection, balloon dilation, and surgical myotomy, ${ }^{3}$ each of which can result in submucosal fibrosis, obliteration of surgical and endoscopic planes, and increased difficulty of myotomy. A number of groups have now published case series (5-15 cases per series) of POEM following Heller myotomy that demonstrate excellent short-term results and improvements in both subjective patient parameters and objective outcomes. ${ }^{5-8}$ At some centers, endoscopic myotomy is now the procedure of choice for recurrent or persistent symptoms following surgical myotomy. 
In this issue of The Journal, Sanaka et al. ${ }^{9}$ report their experience of per oral endoscopic re-myotomy in a patient 25 years after Heller myotomy approached by left thoracotomy. When encountered with severe fibrosis and obliteration of the submucosal space in the distal esophagus, the authors persevered and created a second separate submucosal tunnel (double-tunnel POEreM) through which a successful myotomy was performed and resulted in a good functional short-term outcome. This double-tunnel endoscopic redo myotomy reported here and by others ${ }^{5,10}$ represents a natural evolution of a safe and effective technology for which we can expect to see further innovation and advancement. Further, this report is an exemplary demonstration of a productive collaboration between thoracic surgery and gastroenterology services that will continue to foster the ascent of POEM and other advanced endoscopic techniques.

\section{References}

1. Bhayani NH, Kurian AA, Dunst CM, Sharata AM, Rieder E, Swanstrom LL. A comparative study on comprehensive, objective outcomes of laparoscopic Heller myotomy with per-oral endoscopic myotomy (POEM) for achalasia. Ann Surg. 2014;259:1098-103.

2. Inoue H, Sato H, Ikeda H, Onimaru M, Sato C, Minami H, et al. Per-oral endoscopic myotomy: a series of 500 patients. J Am Coll Surg. 2015;221:256-64.

3. NOSCAR POEM White Paper Committee, Stavropoulos SN, Desilets DJ, Fuchs KH, Gostout CJ, Haber G, Inoue H, et al. Per-oral endoscopic myotomy white paper summary. Gastrointest Endosc. 2014;80:1-15.

4. Petersen RP, Pellegrini CA. Revisional surgery after Heller myotomy for esophageal achalasia. Surg Laparosc Endosc Percutan Tech. 2010;20:321-5.

5. Li QL, Yao LQ, Xu XY, Zhu JY, Xu MD, Zhang YQ, et al. Repeat peroral endoscopic myotomy: a salvage option for persistent/recurrent symptoms. Endoscopy. 2016;48:134-40.

6. Zhou PH, Li QL, Yao LQ, Xu MD, Chen WF, Cai MY, et al. Peroral endoscopic remyotomy for failed Heller myotomy: a prospective single-center study. Endoscopy. 2013;45:161-6.

7. Onimaru M, Inoue H, Ikeda H, Yoshida A, Santi EG, Sato H, et al. Peroral endoscopic myotomy is a viable option for failed surgical esophagocardiomyotomy instead of redo surgical Heller myotomy: a single center prospective study. J Am Coll Surg. 2013;217:598-605.

8. Vigneswaran Y, Yetasook AK, Zhao JC, Denham W, Linn JG, Ujiki MB. Peroral endoscopic myotomy (POEM): feasible as reoperation following Heller myotomy. J Gastrointest Surg. 2014;18:1071-6.

9. Sanaka MR, Thota PN, Murthy SC, Raja S. Creation of a second submucosal tunnel enabled successful per-oral endoscopic myotomy (POEM). J Thorac Cardiothoracic Surg. 2016;151:e101-2.

10. Kumbhari V, Tieu AH, Azola A, Saxena P, Ngamruengphong S, El Zein MH, et al. Double peroral endoscopic myotomy for achalasia. Gastrointest Endosc. 2015;82:953. 